\title{
Palmitoylethanolamide Protects Against the Amyloid- $\beta 25-35$ - Induced Learning and Memory Impairment in Mice, an Experimental Model of Alzheimer Disease
}

\author{
Giuseppe D'Agostino', Roberto Russo', Carmen Avagliano', Claudia Cristiano', Rosaria Meli' and \\ Antonio Calignano*,
}

'Department of Experimental Pharmacology, Faculty of Pharmacy, University of Naples Federico II, Naples, Italy

\begin{abstract}
Alzheimer disease (AD) is the most common form of neurodegenerative dementia. Amyloid- $\beta$ deposition, neurofibrillary tangle formation, and neuro-inflammation are the major pathogenic mechanisms that in concert lead to memory dysfunction and decline of cognition. Palmitoylethanolamide (PEA) is the naturally occurring lipid amide between palmitic acid and ethanolamine. Despite its clear role in inflammation and pain control, only limited in vitro evidence exist about a role for PEA in neurodegenerative diseases. Here we describe the neuroprotective activities of PEA in mice injected intracerebroventricularly with amyloid- $\beta$ 25-35 (Ab25-35) peptide $(9 \mathrm{nmol})$. We used spatial and non-spatial memory tasks to evaluate learning and memory dysfunctions. Ab25-35 injection significantly impaired spontaneous alternation performances, water maze spatial reference and working-like memory, and novel object recognition test. PEA was administered once a day $(3-30 \mathrm{mg} / \mathrm{kg}$, subcutaneously), starting $3 \mathrm{~h}$ after Ab25-35, for I or 2 weeks. PEA reduced $(10 \mathrm{mg} / \mathrm{kg})$ or prevented $(30 \mathrm{mg} / \mathrm{kg})$ behavioral impairments induced by Ab25-35 injection. PEA failed to rescue memory deficits induced by Ab25-35 injection in peroxisome proliferator-activated receptor- $\alpha$ (PPAR- $\alpha$ ) null mice. GW7647 (2-(4-(2-(I-cyclohexanebutyl)-3cyclohexylureido)ethyl)phenylthio)-2-methylpropionic acid; $5 \mathrm{mg} / \mathrm{kg}$ per day), a synthetic PPAR- $\alpha$ agonist, mimicked the effect of PEA. Acute treatment with PEA was ineffective. According with the neuroprotective profile of PEA observed during behavioral studies, experimental molecular and biochemical markers induced by Ab25-35 injection, such as lipid peroxidation, protein nytrosylation, inducible nitric oxide synthase induction, and caspase3 activation, were reduced by PEA treatment. These data disclose novel findings about the therapeutic potential of PEA, unrevealing a previously unknown therapeutic possibility to treat memory deficits associated with AD.

Neuropsychopharmacology (2012) 37, 1784-1792; doi:I0.1038/npp.2012.25; published online I4 March 2012
\end{abstract}

Keywords: fatty acid acyl ethanolamine; peroxisome proliferator-activated receptors; hippocampus; water maze; Y-maze; dementia

\section{INTRODUCTION}

Alzheimer disease (AD) is the most common form of neurodegenerative dementias. $\mathrm{AD}$ has a complex and progressive pathological phenotype characterized by hypometabolism and impaired synaptic function, followed by pathological burden (Zawia et al, 2009). Amyloid- $\beta$ deposition, neurofibrillary tangle formation, and neuro-inflammation are the major pathogenic mechanisms that act in concert to produce memory dysfunction and decline of cognition. To date, there is no specific treatment for $\mathrm{AD}$, and the progressive and multifaceted degenerative pheno-

* Correspondence: Professor A Calignano, Department of Experimental Pharmacology, Faculty of Pharmacy, University of Naples Federico II, Via D. Montesano 49,80131 Naples, Italy, Tel: + 39 (0) 816784II, Fax: + 39 (0) 81678403, E-mail: calignan@unina.it

Received 4 October 2011; revised 23 January 2012; accepted 14 February 2012 type suggests that new successful treatment strategies need to be equally multi-faceted and stage-specific.

Palmitoylethanolamide (PEA), the naturally occurring amide between ethanolamine and palmitic acid, is an endogenous lipid and belongs to the family of the fatty acid ethanolamides (FAEs). PEA is abundant in mammalian brain. As in the case of other FAEs, the production of PEA occurs through an on-demand synthesis within lipid bilayer (Cadas et al, 1996). PEA displays a considerable pharmacological potential when used as a drug (Lo Verme et al, 2005a; LoVerme et al, 2005b), or when its endogenous levels are enhanced by the inhibition of its catabolism (Solorzano et al, 2009).

The first evidence of the potential benefit of FAEs was found in the early 1940s, when Coburn and Moore (1943) reported the antipyretic properties of the dried chicken egg yolk in children with rheumatic fever. Ten years later, the lipid fraction from egg yolk was identified as the component responsible for this effect (Coburn et al, 1954), and it was 
also shown to be effective in reducing experimental allergy (Long and Martin, 1956). PEA was then identified to be the active component of this lipid fraction (Kuehl et al, 1957), and later, it was also found to be present in mammalian tissue (Bachur et al, 1965). After the discovery of its antiinflammatory properties, PEA has been clinically tested and used to treat respiratory symptoms caused by the influenza virus (Masek et al, 1974).

The potential applications of this lipid amid remained overlooked; however, until the characterization of its antiinflammatory (Mazzari et al, 1996), analgesic (Calignano et al, 1998, 2001), and anticonvulsant (Lambert et al, 2001) properties, and the identification of peroxisome proliferator-activated receptor- $\alpha(\operatorname{PPAR}-\alpha)$ as its primary intracellular molecular target (Lo Verme et al, 2005a; LoVerme et al, 2006; D'Agostino et al, 2007; Melis et al, 2008; Scuderi et al, 2011). PPARs are ligand-activated transcription factors belonging to the nuclear receptor superfamily. Three different subtypes have been described, namely PPAR- $\alpha,-\beta / \delta$ and, $-\gamma$, all of which display distinct physiological functions dependent on their differential ligand-activation profiles and tissue distribution (Kliewer et al, 1994; Forman et al, 1996). Both PPAR- $\alpha$ and $-\gamma$ subtypes regulate in vivo and in vitro inflammatory responses (Devchand et al, 1996; Delerive et al, 2001).

Both PEA and PPAR- $\alpha$ are present in the central nervous system (CNS), although their functions in this district, such as their possible neuroprotective potential, are largely unknown. We have reported that some of the analgesic properties of PPAR- $\alpha$ agonists (including PEA) have a likely centrally mediated component, and that the central PPAR- $\alpha$ activation may mediate a central tissue reprogramming away from central inflammation and sensitization (D'Agostino et al, 2007; D'Agostino et al, 2009; Sasso et al, 2011). Considering the anti-inflammatory properties of PEA, and the existence of a PEA/PPAR- $\alpha$ signaling at CNS level, we hypothesized that PEA may exert neuroprotective effect in an experimental model of neurodegenerative dementia. The aim of the present study was, therefore, to evaluate the effect of PEA treatment in an experimental model of $\mathrm{AD}$, such as the intracerebroventricular injection of aggregated amyloid- $\beta$ fragment $25-35$ (Ab25-35) in mice.

\section{MATERIALS AND METHODS}

\section{Animals}

All procedures met the European guidelines for the care and use of laboratory animals (86/609/ECC and 2010/63/UE), and those of the Italian Ministry of Health (DL 116/92). Male wild-type (WT) and PPAR- $\alpha-/-$ (B6.129S4-SvJaePparatm1Gonz) mice previously backcrossed to C57BL6 mice for 10 generations, were bred in our animal facility, where a colony was established and maintained by heterozygous crossing. Mice were genotyped as described on the supplier webpage (http://jaxmice.jax.org), with minor modifications. DNA was extracted from tails using the RedExtract kit (Sigma-Aldrich, Milan, Italy). All animals were maintained on a 12-h light/12-h dark cycle with free access to water and standard laboratory chow.

\section{Chemicals}

PEA and GW7647 (2-(4-(2-(1-cyclohexanebutyl)-3-cyclohexylureido)ethyl)phenylthio)-2-methylpropionic acid) were from Tocris (Bristol, UK). PEA and GW7647 were dissolved in PEG and Tween 80 2:1 (Sigma-Aldrich), and kept over night under gentle agitation with a micro stirring bar. Before injection, sterile saline was added so that the final concentrations of PEG and Tween 80 were 20 and $10 \%$ $\mathrm{v} / \mathrm{v}$, respectively.

Drugs were injected subcutaneously (s.c.) in a volume of $100 \mu \mathrm{l}$ per $30 \mathrm{~g}$ of body weight. The Ab25-35 and scrambled Ab25-35 (ScAb) peptide were from NeoMPS (Strasbourg, France) or Genepep (Montpellier, France). They were dissolved in sterile bi-distilled water at a concentration of $3 \mathrm{mg} / \mathrm{ml}$, and stored at $-20^{\circ} \mathrm{C}$ until use. To prepare 'aged' $\mathrm{Ab} 25-35$ peptide, peptides were aggregated by incubation at $3 \mathrm{mg} / \mathrm{ml}$ in sterile bidistilled water at $37^{\circ} \mathrm{C}$ for 4 days. Peptides were administered intracerebroventricularly (i.c.v.) in a final volume of $3 \mu \mathrm{l} \mathrm{per}$ mouse, as previously described (Maurice et al, 1996).

\section{Study Design}

In Figure 1 are reported the experimental setting used during this study. Amyloid aggregates were generated and i.c.v. injected as reported above. To evaluate its neuroprotective profile, PEA was first administered once a day, with treatment starting $3 \mathrm{~h}$ after the amyloid injection. After 7 days of treatment, mice were tested for spontaneous alternation in the Y-maze test. The day after (8 days after amyloid), they were submitted to the Mooris water-maze task for 5 days. After a day of resting (day 13), the same mice were submitted (day 14) to a different water-maze procedure to specifically evaluate working memory (Figure 1 flow chart A). A different cohort of mice was treated, as reported above, to evaluate the effect of PEA on novel object recognition (NOR) test, and GW7647 on NOR and Y-maze test. To evaluate acute anti-amnesic effect, a different group of mice was treated i.c.v. with amyloid, as reported above, and than treated with a single dose of PEA $30 \mathrm{~min}$ before being tested (Figure 1 flow chart B). For molecular and biochemical analysis, mice were daily treated with PEA and euthanized after 5 days (Figure 1 flow chart C).

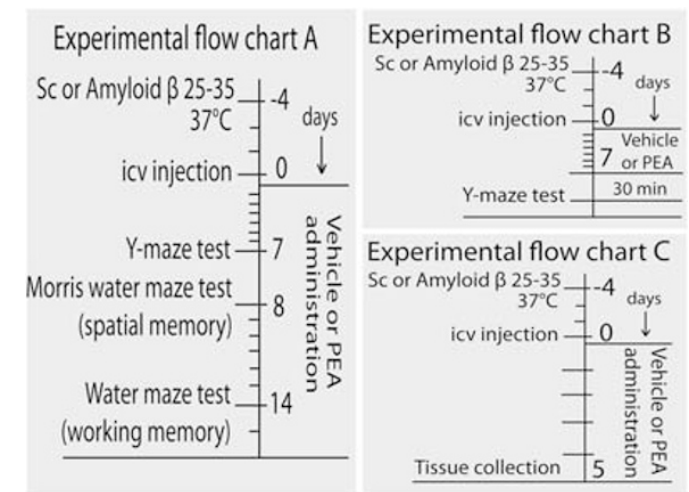

Figure I Experimental flow charts. (A) Experimental design for behavioral studies with daily treatment. (B) Experimental design for behavioral studies with acute treatment. (C) Experimental design for molecular, and biochemical and molecular analysis. 


\section{Spontaneous Alternation Performances}

Each mouse, naive to the apparatus, was placed at the end of one arm in a Y-maze (three arms, $40 \mathrm{~cm}$ long, $120^{\circ}$ separate) and allowed to move freely through the maze during a single 5 -min session. The series of arm entries, including possible returns into the same arm, was recorded visually. An alternation was defined as entries into all three arms on consecutive trials. The number of the total possible alternations was therefore the total number of arm entries minus two, and the percentage of alternation was calculated as (actual alternations/total alternations) $\times 100$.

\section{Spatial Learning and Memory Tests}

The water maze was a circular pool (diameter $170 \mathrm{~cm}$, height $60 \mathrm{~cm}$ ). The water temperature, $23 \pm 1{ }^{\circ} \mathrm{C}$, light intensity, external cues in the room, and water opacity were rigorously reproduced. A transparent Plexiglas non-slippery platform (diameter $10 \mathrm{~cm}$ ) was immersed under the water surface $(1.5 \mathrm{~cm})$ during acquisition trails. Swimming was recorded using a camera capture, and analyzed using a videotrack software (Any-maze, Stoelting, Wood Dale, IL, USA). The software divided the pool into four quadrants. Training consisted of four swims per day for 5 days, with about a 15min inter-trial time. Start positions were pseudo-randomly selected, and each animal was allowed a 90-s swim to find the platform. Once the mouse reached the platform, it was left $20 \mathrm{~s}$ on the platform. The latency, expressed as mean \pm SEM, was calculated for each training day.

A probe test was performed $1 \mathrm{~h}$ after the last swim on day 5 . The platform was removed and each animal was allowed a free 60-s swim. The start position for each mouse corresponded to one of two positions remote from the platform location in counterbalanced order. The platform quadrant was termed the training quadrant, and the percentage of time spent in the training quadrant was determined.

\section{Water-Maze Working Memory}

A procedure for specifically assessing the short-term memory component was then performed for 3 days. The platform location changed every day, but not among trials. Each animal was allowed four trials per day, with a 2-min inter-trial time interval. Data represent the mean performance over days for each trial. The first trial is an informative sample trial, in which the animal is allowed to swim to the platform in its new location. During each other trial, the mouse involves its working memory component to increase its ability to reach the platform location (Yamada et al, 1999; Maurice et al, 2008). The decrease in latency between trials 1 and 4 could therefore be calculated to have a direct measure of the working memory performance.

\section{NOR Test}

The NOR test consisted of two sessions: a training session followed by a retention trial $24 \mathrm{~h}$ later. Mice were habituated to the testing arena for 2 consecutive days before the test. During the training session, two different objects (A and B) were placed in the testing arena. Each animal was allowed to explore the objects for $5 \mathrm{~min}$. The mouse was considered to be exploring the object when the head of the animal was facing the object, or the animal was touching or sniffing the object. The total time spent exploring each object was recorded by a trained observer blind to treatments, and expressed as percentage of total exploration time. In the retention session, one identical and one novel object (A and $\mathrm{C}$ ) were used. A mouse was allowed to explore the objects for $5 \mathrm{~min}$, and the time spent exploring each object was recorded. Exploration time was normalized as percentage of total exploration time. Preference for the novel object was considered as successful retention of memory for the familiar object.

\section{Rotarod Test}

Mice were habituated to the testing room for $30 \mathrm{~min}$. Rotarod maximal r.p.m. was 40.0, and the acceleration time was 200 s. Mice were given six trials for 2 consecutive days.

\section{Preparation of Total Tissue Protein Extracts and Western Blot Analysis}

Hippocampi were homogenized on ice-cold lysis buffer (10 mM Tris-HCl, $20 \mathrm{mM}, \mathrm{pH} 7.5,10 \mathrm{mM} \mathrm{NaF}, 150 \mathrm{mM}$ $\mathrm{NaCl}, 1 \%$ Nonidet $\mathrm{P}-40,1 \mathrm{mM}$ phenylmethylsulphonyl fluoride, $1 \mathrm{mM} \mathrm{Na} 3 \mathrm{VO} 4$, leupeptin, and trypsin inhibitor $10 \mu \mathrm{g} / \mathrm{ml} ; 0.25 \mathrm{ml} / 50 \mathrm{mg}$ tissue). After $1 \mathrm{~h}$, tissue lysates were centrifuged at 14000 r.p.m. for $15 \mathrm{~min}$ at $4^{\circ} \mathrm{C}$, and the supernatant was stored at $-80^{\circ} \mathrm{C}$ until use. Protein content was measured using bovine serum albumin (Sigma-Aldrich) as a standard. Protein lysates $(70 \mu \mathrm{g})$ were separated on SDS-polyacrylamide gels, and membranes were incubated with anti-inducible nitric oxide synthase (iNOS; cat. no. 610432, BD Biosciences, from Becton Dickinson, Buccinasco, Italy), and anti-cleaved-caspase-3 (fragment p17) or -uncleaved-caspase-3 (fragment p30; cat. no. 9662, Cell Signaling, from Euroclone, Milan, Italy). Signals were visualized using ImageQuant 400 equipped with Quantity One Software 4.6.3 (GE Healthcare, Milan, Italy).

\section{Lipid Peroxidation Measures}

Mice were killed by decapitation, and brains were rapidly removed, weighed, and kept in liquid nitrogen until assayed. After thawing, brains were homogenized in cold methanol $(1: 10, \mathrm{w} / \mathrm{v})$, centrifuged at $1000 \mathrm{~g}$ for $5 \mathrm{~min}$, and the supernatant collected. Homogenate was added to a solution containing FeSO 4 mM, H2SO $40.25 \mathrm{M}$, and xylenol orange $1 \mathrm{mM}$, and incubated for $30 \mathrm{~min}$ at room temperature. Absorbance was measured at $580 \mathrm{~nm}$ (A5801), and $10 \mathrm{ml}$ of cumene hydroperoxide (CHP) $1 \mathrm{mM}$ was added to the sample and incubated for $30 \mathrm{~min}$ at room temperature, to determine the maximal oxidation level. Absorbance was measured at $580 \mathrm{~nm}\left(\mathrm{~A}_{580} 2\right)$. The level of lipid peroxidation was determined as CHP equivalents according to: $\mathrm{CHP}$ equiv. $=\mathrm{A}_{580} 1 / \mathrm{A}_{580} 2 \mathrm{X}(\mathrm{CHP}(\mathrm{nmol})) \times$ dilution, and expressed as CHP equiv. per wet tissue weight and than as percentage of control (Maurice et al, 1996).

\section{Statistical Analysis}

Data are expressed as mean \pm SEM. Two-groups comparisons were made using the Student's $t$-test. When more than two 
groups, data were analyzed using one-way ANOVA followed by the Dunnett's post-hoc multiple comparison test. Watermaze escape latencies were analyzed over trials using repeated measures ANOVA. For the probe test of Morris water maze, the time spent in the training quadrant was analyzed $v s$ the chance level $(15 \mathrm{~s})$; for water-maze working memory, improvement between trial 1-4 was analyzed $v s$ the chance level of 0 (no improvement); and for NOR, preference for the new object during the retention trail was analyzed $v s$ the chance level of $50 \%$ using Wilcoxon signed-rank test. The level of statistical significance was $P<0.05$.

\section{RESULTS}

\section{PEA Counteracts the Ab25-35-Induced Learning Deficits}

The possible neuroprotective effects of PEA were first evaluated on the appearance of Ab25-35-induced learning deficits. As previously reported (Maurice et al, 1996), acute i.c.v. injection of Ab25-35 induced, 7 days after, a marked impairment of spontaneous alternation performances compared with ScAb25-35. PEA was administered at 3, 10 or $30 \mathrm{mg} / \mathrm{kg}$ s.c. once per day, with treatment starting $3 \mathrm{~h}$ after the i.c.v. administration of the Ab25-35 peptide. Seven days after, PEA treatment resulted in a dose-dependent attenuation of the Ab25-35-induced spontaneous alternation impairments $\left(\mathrm{F}_{(4,39)}=5957, P<0.0001\right.$; Figure $\left.2 \mathrm{a}\right)$; whereas no significant differences were found in the number of arm entries (Figure 2b). Post-hoc analysis revealed that the dose of $30 \mathrm{mg} / \mathrm{kg}$ was the most active, producing a complete prevention of the appearance of Ab25-35-induced spontaneous alternation deficits (Figure $2 \mathrm{a}$ ).

\section{Spatial and Reference Working Memory}

The effect of Ab25-35 peptide injection on spatial and reference working memory was analyzed using the Morris

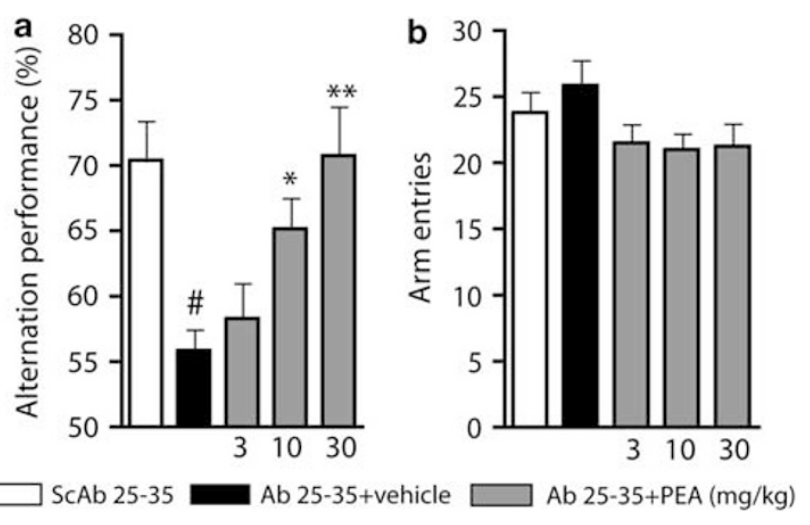

Figure 2 Neuroprotective effect of palmitoylethanolamide (PEA) on amyloid- $\beta$ 25-35 (Ab25-35)-induced spontaneous alternation deficits in mice. (a) Alternation performances and (b) total numbers of arm entries. Mice were injected intracerebroventricularly (i.c.v.) with scrambled Ab2535 (ScAb25-35) or Ab25-35 peptide (9 nmol). Mice (8-10 per group) received a daily subcutaneous (s.c.) injection of vehicle or PEA (3, 10 , and $30 \mathrm{mg} / \mathrm{kg}$ ). After 7 days, mice were examined for spontaneous alternation in the Y-maze apparatus. ${ }^{\#} P<0.05$ vs (ScAb25-35 + vehicle)-treated group; $* P<0.05, \quad * * P<0.01$ vs (Ab25-35+vehicle)-treated group; Dunnett's test. water-maze procedure. Animals received ScAb $(9 \mathrm{nmol})$ or Ab25-35 ( $9 \mathrm{nmol}$ ), and were submitted 8 days after to a reference memory procedure. They had to learn the location of an invisible platform set at a fixed position, by performing four swimming per day for 5 consecutive days.

The acquisition profiles of ScAb-treated mice showed a significant diminution of swimming latencies, which is indicative of learning abilities. By contrast, the latencies showed by Ab25-35-treated mice were significantly higher for all training trials, as compared with ScAb-treated control group. PEA treatment attenuated this learning impairment in a dose-dependent manner (Figure 3a; effect of treatment $\left.\mathrm{F}_{(3,132)}=6.88, p=0.001\right)$. Although the $3-\mathrm{mg} / \mathrm{kg}$ dose was ineffective (data not shown), the dose of $30 \mathrm{mg} / \mathrm{kg}$ almost completely normalized the learning profile of mice (Figures $3 \mathrm{a}$ and $\mathrm{b}$ ). Supporting a protective role for PEA against Ab25-35 memory impairment, the probe test revealed that $\mathrm{ScAb}$ - and $\mathrm{PEA}(30 \mathrm{mg} / \mathrm{kg})$-treated mice explored preferentially the training quadrant at a similar extent (Figure 3c; $P<0.05$ ). Although the analysis of swimming speed revealed no significant difference among groups (Figure 3d), we found that the Ab25-35-treated mice displayed a significant increase in tigmotactic behavior during the first trail of the first day (when mice were naïve to the apparatus) that is indicative of higher anxiety. PEA treatment normalized this anxiety behavior (Figure 3e; $\left.\mathrm{F}_{(3,23)}=4.155, p=0.0288\right)$.

Animals were then submitted to the working memory procedure. During 3 days, they had to learn the location of a platform changing every day, by performing four swimming with a short inter-trial interval of $2 \mathrm{~min}$. Animals learned the new platform location on sample trial 1 and then gradually improved their competence based on their working memory ability. Results showed that ScAb-treated WT mice were able to learn the variable platform location, as latencies significantly decreased over trials (Figure 3g). The Ab2535-treatment impaired this acquisition. On trial 4, a significant difference in latency was measured between the $\mathrm{ScAb}$ - and Ab25-35 (9 nmol)-treated groups. Improvement was also analyzed in terms of difference between trial 1 and trial 4 (Figure $3 \mathrm{~h}$ ). The ScAb-treated group showed a latency decrease significantly higher than zero. PEA treatment showed a normalization trend respect to the impairment induced by $\mathrm{Ab} 25-35$, with a learning profile comparable to that one of ScAb25-35-treated mice (Figures $3 g$ and $h$ ).

\section{PEA Does not Exert Acute Anti-Amnesic Effect Against Ab25-35-Induced Memory Impairments}

Behavioral deficits induced by Ab25-35 seem to be related to alterations in cholinergic and glutamatergic corticolimbic systems (Maurice et al, 1996; Olariu et al, 2001); therefore, drugs boosting these systems may exert acute anti-amnesic properties, in a way independent of their action on neurodegeneration progression. To test this possibility, we performed an additional experiment, and a possible acute anti-amnesic effect of PEA was examined in mice centrally injected with $\mathrm{ScAb}$ or Ab25-35 peptide 7 days before. The spatial working memory was examined in the Y-maze test. Mice received PEA $(30 \mathrm{mg} / \mathrm{kg}) 30 \mathrm{~min}$ before the test session. In mice treated with Ab25-35, the alternation performance was about 55\%, and PEA treatment did not 

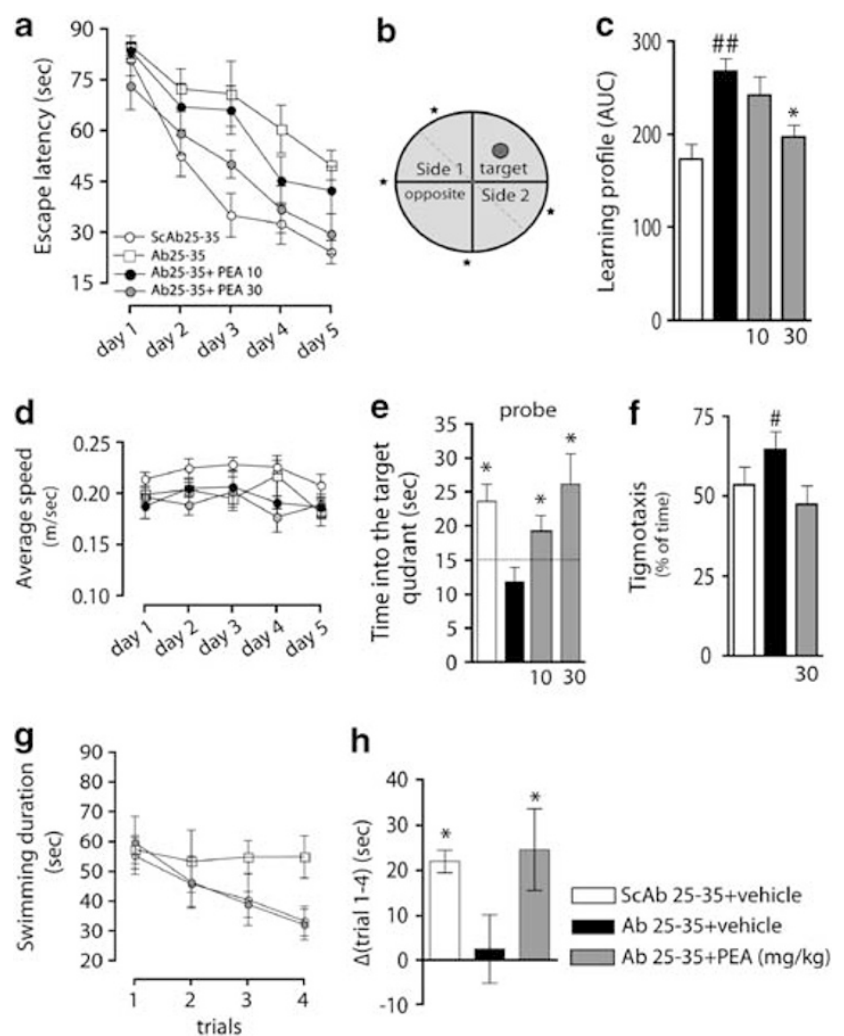

Figure 3 Neuroprotective effect of palmitoylethanolamide (PEA) on amyloid- $\beta$ 25-35 (Ab25-35)-induced spatial learning and memory deficits in mice. Animals received a single intracerebroventricularly (i.c.v.) administration of scrambled Ab25-35 (ScAb25-35) or Ab25-35 (9 nmol), and they were daily treated with a subcutaneous (s.c.) injection of vehicle or PEA $(10$ and $30 \mathrm{mg} / \mathrm{kg})$. After 8 days, mice were tested in the Morris Water Maze task. (a) Acquisition profiles: mice were submitted to acquisition of an invisible platform placed in a fixed location (target quadrant) with four swims per day during 5 days. (b) Apparatus drawing. (c) Acquisition profiles visualized as area under the curve (AUC) indicative of learning abilities. (d) Graph showing mice speed during the execution of the task. (e) Probe test sessions: $2 \mathrm{~h}$ after the last swim on day 5, the platform was removed, and the time spent in the target quadrant analyzed; $* P<0.05$ vs a change level of $15 \mathrm{~s}$ (Wilcoxon signed-rank test). ( $f$ ) Tigmotaxis during the first swim of the first day indicative of an anxietyrelated behavior; ${ }^{\#} P<0.05$ vs ScAb25-35 group. On day 14, mice were submitted to acquisition of a platform location changing daily (working memory procedure). (g) Acquisition profiles and (h) improvements between trial I and 4 ; $* P<0.05$ vs a change of zero (Wilcoxon signedrank test).

produce any improvement (Figures $4 \mathrm{a}$ and $\mathrm{b}$ ). Central administration of $\mathrm{ScAb}$ or Ab25-35 peptide, or the subsequent i.p. treatment with PEA did not change the total number of arm entries (Figure $4 \mathrm{~b}$ ), speed (Figure 4c), or distance traveled during test execution (Figure 4d).

\section{Neuroprotective Effects of PEA Against Ab25-35- Induced Toxicity are Dependent on PPAR- $\alpha$}

Previous studies have shown that PEA and other lipid amides, such as oleoylethanolamide, activate the antiinflammatory nuclear receptor PPAR- $\alpha$ in a range of concentrations that normally occurs in mammalian tissue (Fu et al, 2003; Lo Verme et al, 2005a). To assess whether the absence of functional PPAR- $\alpha$ could affect the protective effect of PEA against Ab25-35-induced learning and

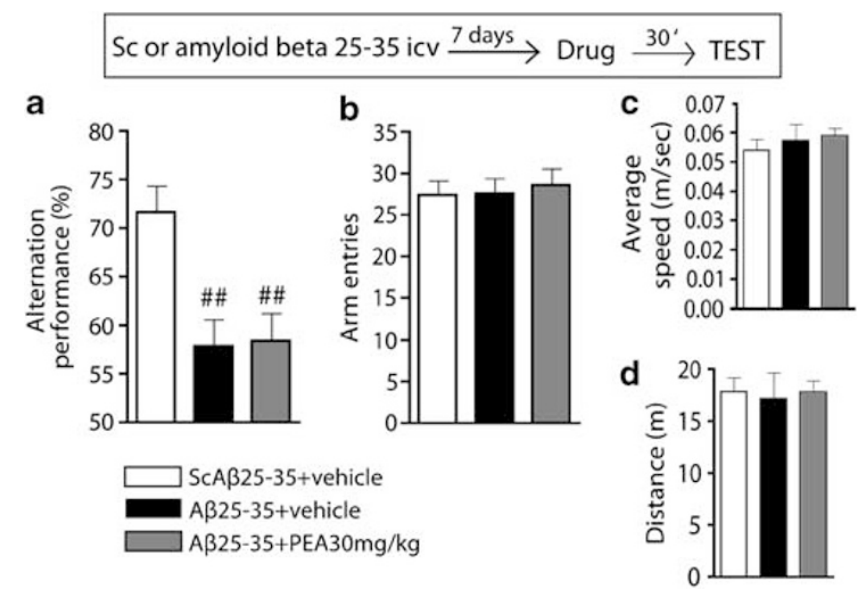

Figure 4 Anti-amnesic effect of acute palmitoylethanolamide (PEA) on amyloid- $\beta$ 25-35 (Ab25-35)-induced spontaneous alternation deficits in mice. (a) Alternation performances, (b) total numbers of arm entries, (c) average speed during testing, and (d) distance traveled in the apparatus. Mice were injected intracerebroventricularly (i.c.v.) with scrambled Ab25-35 (ScAb25-35) or Ab25-35 peptide (9 nmol). After 7 days, mice (nine per group) received a single intraperitoneal injection of vehicle or PEA (30 mg/kg), 30 min before being examined for spontaneous alternation in the $Y$-maze apparatus. ${ }^{\# \#} P<0.01$ vs (ScAb25-35 + vehicle)-treated group; Dunnett's test.

memory impairments, we tested the most effective dose, $30 \mathrm{mg} / \mathrm{kg}$, in PPAR- $\alpha$ knock-out mice. As the role of PPAR- $\alpha$ on brain functions is largely unknown, we first verified if the genetic ablation of PPAR- $\alpha$ could produce phenotypic traits relevant to the present study. As shown in Figure 5, PPAR- $\alpha$ knock-out male mice and their WT littermate controls (8-9 weeks of age) did not differ when tested in the Y-maze apparatus (Figures $5 \mathrm{a}$ and $\mathrm{b}$ ) or Morris water-maze task (Figures $5 \mathrm{c}$ and $\mathrm{d}$ ). In a different group of PPAR- $\alpha$ knock-out and WT mice, we therefore tested the neuroprotective effect of PEA (30 mg/kg per day) against Ab25-35induced learning and memory impairments. PEA did not protect PPAR- $\alpha$ knock-out mice against Ab25-35-induced learning and memory impairments. PEA failed to normalize spontaneous alternation performances of PPAR- $\alpha$ knockout mice after 7 days of treatment (Figures 6a and b). To further validate the role of PPAR- $\alpha$ receptor, we also tested a synthetic and selective PPAR- $\alpha$ agonist, GW7647. GW7647 $(5 \mathrm{mg} / \mathrm{kg}$ per day) reduced the spontaneous alternation deficit caused by Ab25-35 (Figure 6c). As expected, GW7647 was ineffective when tested in PPAR- $\alpha$ knock-out mice (data not shown). To extend our observations to a non-spatial form of cognition, we tested a different cohort of mice in the NOR test. Both PEA ( $30 \mathrm{mg} / \mathrm{kg}$ per day) and GW7647 (5 mg/kg per day) reduced the impairment induced by $\mathrm{Ab} 25-35$ in the NOR test evaluated after a retention interval of $24 \mathrm{~h}$ (Figure 6d). Increased exploration of the novel object was interpreted as successful retention of memory for the familiar object. Ab25-35-treated mice did not show a preference for the novel object after $24 \mathrm{~h}$, whereas ScAb25-35, and PEA- or GW-treated mice had a percentage of novel object exploration significantly above the chance level of 50\% (Figure 6d). We finally tested the same cohort of mice for motor coordination and motor learning by means of repeated rotarod testing. Mice were 

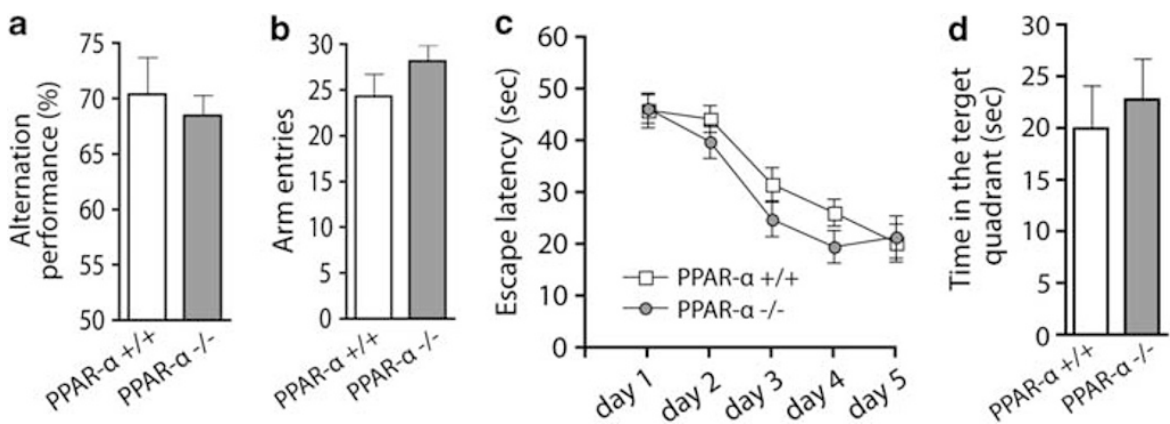

Figure 5 Memory profiles of peroxisome proliferator-activated receptor- $\alpha$ (PPAR- $\alpha$ ) knock-out mice. Effect of the absence of functional PPAR- $\alpha$ on (a) spontaneous alternation perfomances, and (b) number of arm entries in the Y-maze test. (c) Spatial learning profile, and (d) spatial memory recall in the Morris Water Maze task. Wild-type (WT; $+/+; n=8)$ and PPAR- $\alpha$ knock-out $(-/-; n=9)$ littermate male mice were tested at 8-9 weeks of age. No significant differences were found.

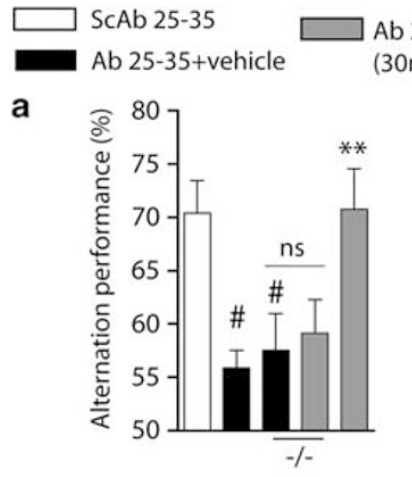

Ab 25-35+PEA Ab 25-35+GW7647 $\quad(5 \mathrm{mg} / \mathrm{kg})$

c
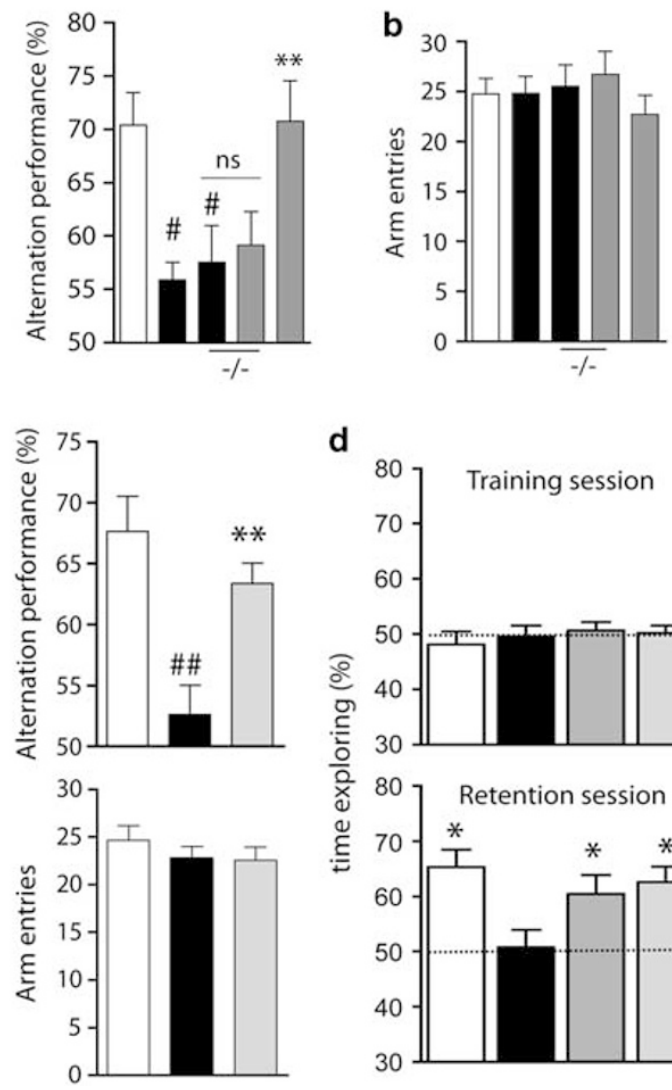

d

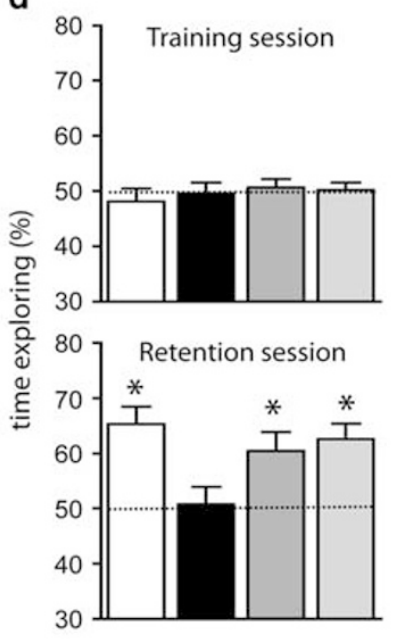

Figure 6 Neuroprotective effects of palmitoylethanolamide (PEA) against amyloid- $\beta$ 25-35 (Ab25-35)-induced toxicity are dependent on peroxisome proliferator-activated receptor- $\alpha$ (PPAR- $\alpha$ ). (a) Alternation performances and (b) total numbers of arm entries. PPAR- $\alpha$ wild-type (WT; $+/+)$ and knock-out $(-1-)$ mice were injected intracerebroventricularly (i.c.v.) with scrambled Ab25-35 (ScAb25-35) or Ab25-35 peptide ( 9 nmol). Mice (810 per group) received a daily subcutaneous (s.c.) injection of vehicle or PEA $(30 \mathrm{mg} / \mathrm{kg})$. (c) GW7647 (2-(4-(2-(I-cyclohexanebutyl)-3-cyclohexylureido)ethyl)phenylthio)-2-methylpropionic acid; $5 \mathrm{mg} / \mathrm{kg}$ per day, s.c.), a synthetic and selective PPAR- $\alpha$ agonist, mimics the effect of PEA. After 7 days, mice were examined for spontaneous alternation in the $Y$-maze apparatus. ${ }^{\#} P<0.05$ or ${ }^{\# \#} P<0.0$ l vs (ScAb25-35 + vehicle)-treated group; ** $P<0.0$ I vs (Ab25-35 + vehicle)-treated group; Dunnett's test. (d) Novel object recognition (NOR) test. Both PEA and GW7647 counteract the impaired novel object recognition induced by Ab25-35 peptide ( $9 \mathrm{nmol}$ ). $* P<0.05$ vs a change level of 50\% (Wilcoxon signed-rank test). tested for 2 consecutive days with six trails per day. Neither amyloid fragment nor pharmacological treatments impaired motor coordination or motor learning. Independently of treatment, all mice had increasing time performance over testing (data not shown).

\section{PEA Reduces Amyloid-Induced Oxidative Stress and Apoptotic Markers}

Biochemical parameters of amyloid toxicity were also analyzed in the hippocampus extracts to validate the neuroprotective activity of PEA. Amyloid peptides, and particularly Ab25-35, induce a massive oxidative stress in forebrain structures. We therefore analyzed some representative biochemical and molecular markers with the aim to support the above reported behavioral observations. As previously reported, Ab25-35 significantly increases the levels of lipid peroxidation, protein nitrosylation, induces iNOS expression, and results in cell death through caspasedependent apoptosis pathways (Figure 7). PEA (30 mg/kg) significantly reduced the $\mathrm{Ab} 25-35$-induced lipid peroxidation increase (Ab 25-35 vs ScAb25-35, $P<0.01 ; \mathrm{Ab} 25-35$ vs Ab25-35 + PEA, $P<0.05$; Figure 7a). PEA $(30 \mathrm{mg} / \mathrm{kg})$ significantly reduced the Ab25-35-induced iNOS induction (iNOs/ $\beta$-actin ratio \pm SEM $(n=4)$, ScAb25-35: $1.055 \pm 0.074$, Ab25-35: $\quad 1.763 \pm 0.12^{\# \#, ~ A b 25-35 ~+~ P E A: ~} 1.368 \pm 0.17^{*}$ $\left({ }^{\# \#} P<0.01\right.$ vs ScAb25-35; ${ }^{\star} P<0.05$ vs Ab25-35, Dunnett's test); Figure $7 \mathrm{c})$. PEA $(30 \mathrm{mg} / \mathrm{kg})$ attenuated $(P=0.055)$ the Ab25-35-induced activation of caspase3 (cleaved caspase3/ caspase3 ratio \pm SEM $(n=4)$, ScAb25-35: $0.435 \pm 0.029$, Ab25-35: $\quad 0.630 \pm 0.031^{\#}, \quad$ Ab25-35 + PEA: $\quad 0.515 \pm 0.037$ ( $P<0.05$ vs ScAb25-35, Dunnett's test); Figure 7d). Overall, this set of data adds further support to the neuroprotective effect of PEA observed during behavioral studies.

\section{DISCUSSION}

The present study discloses a previously unreported therapeutic effect of PEA in an experimental model of AD.

There are two major hallmarks of $\mathrm{AD}$ : neurofibrillary tangles and amyloid aggregates. In rodent brain, Ab25-35 induces, after acute injection or chronic infusion, biochemical changes, morphological alterations, and behavioral impairments reminiscent of $\mathrm{AD}$ physiopathology 


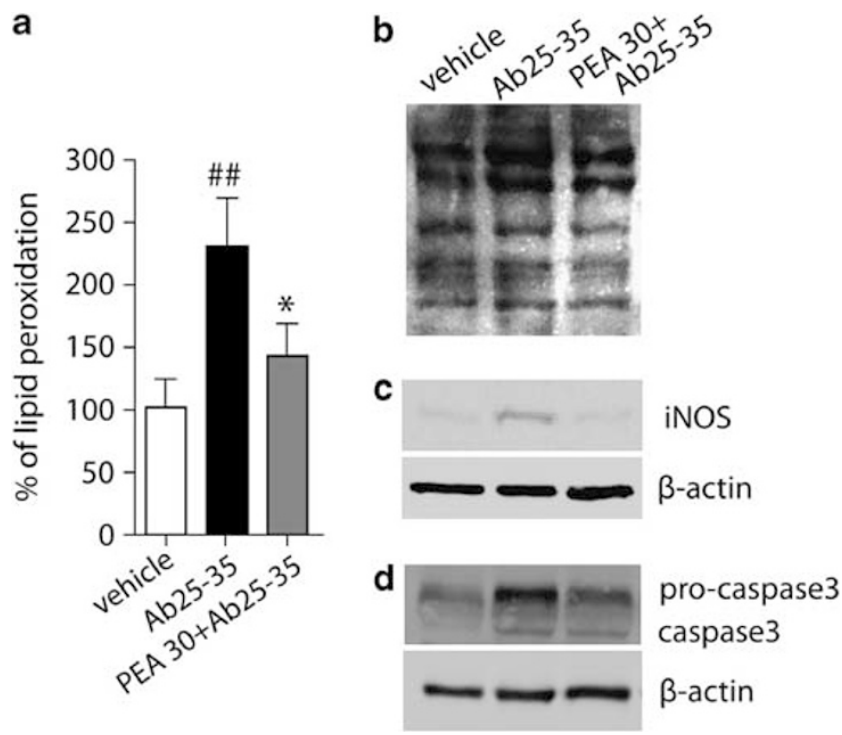

Figure 7 Neuroprotective effects of palmitoylethanolamide (PEA, $30 \mathrm{mg} / \mathrm{kg}$ ) measured using biochemical markers in the hippocampus in scrambled amyloid- $\beta$ 25-35 (ScAb25-35)- and Ab25-35-injected mice, daily treated with vehicle or PEA (30 mg/kg, subcutaneously (s.c.)): (a) lipid peroxidation levels, (b) protein nytrosilation levels; (c) inducible nitric oxide synthase (iNOS) expression; (d) caspase-3 expression. Mice were administered s.c. with PEA or vehicle $3 \mathrm{~h}$ after the intracerebroventricularly (i.c.v.) injection of ScAb or Ab25-35 peptide $(9 \mathrm{nmol})$ and once a day for 5 days.

(Maurice et al, 1996; Delobette et al, 1997). By using Ymaze, water maze, and object recognition tasks, we have shown that a daily treatment with PEA reduces learning and memory deficits caused by the central injection of the pre-aggregated Ab25-35. The protective profile of PEA is dose-dependent, and the dose of $30 \mathrm{mg} / \mathrm{kg}$ fully prevents the working memory-like impairment evaluated as $\mathrm{Y}$ maze alternation performances. The same dose almost completely rescues spatial learning and memory deficits induced by $\mathrm{Ab} 25-35$ when tested in the water-maze task. The restoration of these two aspects of memory performances is of particular interest, as they are highly representative of common clinical features of AD. Patients with $\mathrm{AD}$ show decline in immediate memory span and in working memory as the disease progresses, and they often experience difficulties with spatial orientation in everyday activities (Hort et al, 2007).

Among the different stages of the disease, neuroinflammation and oxidative stress have an important role in pathogenesis. Inflammatory mediators, such as TNF $\alpha$, IL-1, and IL-6, have negative effects on hippocampal long-term potentiation that is considered a cellular model of learning and memory (Bellinger et al, 1993; Stellwagen and Malenka, 2006; Schmid et al, 2009; Tsai et al, 2010). Although there exists a vast literature on the anti-inflammatory properties of PEA, our work is, to the best of our knowledge, the first in vivo study that shows the ability of this endogenous acylethanolamide to rescue experimentally induced memory deficit. Previous studies have shown that PEA and other fatty acid acyl ethanolamines activate the anti-inflammatory nuclear receptor PPAR- $\alpha$ in a range of concentrations that occur normally in tissues (Fu et al, 2003; Lo Verme et al, 2005a). The expression of this nuclear receptor is necessary for exogenous PEA to exert its anti-inflammatory (Lo Verme et al, 2005a) and antioxidant effects (Raso et al, 2011). Our study showed the obligatory role of PPAR- $\alpha$ for the neuroprotective effect of PEA against amyloid toxicity. As expected, our work also showed that a synthetic PPAR- $\alpha$ agonist mimics the pro-cognitive effect of PEA. These data add further support to the notion that this nuclear receptor is the primary molecular target of PEA, and extend our previous finding about the physio-pathological role of PEA/ PPAR- $\alpha$ signaling in the CNS (D'Agostino et al, 2007, 2009). With reference to $\mathrm{AD}$, our behavioral observations in PPAR$\alpha$ knock-out mice are also supported by recent in vitro evidence showing that PEA reduces amyloid-induced astrogliosis through a PPAR- $\alpha$-dependent mechanisms (Scuderi et al, 2011). As part of its transcriptional activity, PPAR- $\alpha$ also induces the expression of genes involved in mitochondrial and peroxisomal fatty acid $\beta$-oxidation (Berger and Moller, 2002; Willson et al, 2000). Peroxisomes have a crucial role for ROS and lipid metabolism, and their importance in brain physiopathology is well established. We hypothesize that PEA acting at PPAR- $\alpha$ receptor could increase the number of peroxisomes and/or the activity of the peroxisomal matrix protein catalase counteracting the redox perturbation following the amyloid excess. Recent studies showed that the PPAR- $\alpha$ agonist fenofibrate is able to promote the survival of cortical neurons in the presence of the NO donors in vitro (Gray et al, 2011). Moreover, the expression of neuronal peroxisomal and peroxisome-related proteins (eg, PPAR- $\alpha$ ) has been reported to change after a challenge with $\mathrm{Ab}$ in vitro (Cimini et al, 2009), supporting the notion that peroxisomal and peroxisome-related proteins may constitute a cellular defense against $\mathrm{Ab}$-mediated oxidative injury. According with this scenario, we demonstrated that behavioral effects exerted by PEA are corroborated by molecular and biochemical evidences, in that PEA reduced the increase of lipid peroxidation, protein nitration, iNOS expression, and the induction of pro-apoptotic pathways induced by Ab25-35.

Although the molecular mechanism underlying the neuroprotective effect of PEA needs further investigations, we provided evidence suggesting that PEA acting at PPAR- $\alpha$ rescues behavioral impairments that can mimic some traits of $\mathrm{AD}$. Considering that PEA is currently used to treat chronic pain, our findings can be worthy of clinical consideration, and they can have immediate utility, at least in the early stages of this pathology.

\section{ACKNOWLEDGEMENTS}

This work was supported by a PRIN 2009 Grant from Ministero dell'Istruzione, dell'Università e della Ricerca (MIUR), Italy, to AC. We are grateful to Luca Giordano and Carmen De Caro for helping with experiments.

\section{DISCLOSURE}

The authors declare no conflict of interests.

\section{Authors contribution}

GD designed experiments, carried out behavioral studies, analyzed data, and wrote the manuscript. RR, CA, CC 
performed research. RR and RM participated in the design of the study. AC conceived the study, participated in its design and coordination, provided financial sources, and wrote the manuscript.

\section{REFERENCES}

Bachur NR, Masek K, Melmon KL, Udenfriend S (1965). Fatty acid amides of ethanolamine in mammalian tissues. J Biol Chem 240: 1019-1024.

Bellinger FP, Madamba S, Siggins GR (1993). Interleukin 1 beta inhibits synaptic strength and long-term potentiation in the rat CA1 hippocampus. Brain Res 628: 227-234.

Berger J, Moller DE (2002). The mechanisms of action of PPARs. Annu Rev Med 53: 409-435.

Cadas H, Schinelli S, Piomelli D (1996). Membrane localization of $\mathrm{N}$-acylphosphatidylethonolamine in central neurons: studies with exogenous phospholipases. J Lipid Mediat Cell Signal 14: 63-70.

Calignano A, La Rana G, Giuffrida A, Piomelli D (1998). Control of pain initiation by endogenous cannabinoids. Nature 394: 277-281.

Calignano A, La Rana G, Piomelli D (2001). Antinociceptive activity of the endogenous fatty acid amide, palmitylethanolamide. Eur J Pharmacol 419: 191-198.

Cimini A, Benedetti E, D’Angelo B, Cristiano L, Falone S, Di Loreto $S$ et al (2009). Neuronal response of peroxisomal and peroxisome-related proteins to chronic and acute Abeta injury. Curr Alzheimer Res 6: 238-251.

Coburn AF, Graham CE, Hahinger J (1954). Effect of egg yolk in diets on anaphylactic arthritis (passive Arthus phenomenon) in the guinea pig. J Exp Med 100: 425-435.

Coburn AF, Moore LV (1943). Nutrition as conditioning factor in the rheumatic state. Am J Dis Child 65: 744-756.

D’Agostino G, La Rana G, Russo R, Sasso O, Iacono A, Esposito E et al (2009). Central administration of palmitoylethanolamide reduces hyperalgesia in mice via inhibition of NF-kappaB nuclear signalling in dorsal root ganglia. Eur J Pharmacol 613: 54-59.

D’Agostino G, La Rana G, Russo R, Sasso O, Iacono A, Esposito E et al (2007). Acute intracerebroventricular administration of palmitoylethanolamide, an endogenous peroxisome proliferatoractivated receptor-alpha agonist, modulates carrageenan-induced paw edema in mice. J Pharmacol Exp Ther 322: 1137-1143.

Delerive P, Fruchart JC, Staels B (2001). Peroxisome proliferatoractivated receptors in inflammation control. J Endocrinol 169: 453-459.

Delobette S, Privat A, Maurice T (1997). In vitro aggregation facilities beta-amyloid peptide-(25-35)-induced amnesia in the rat. Eur J Pharmacol 319: 1-4.

Devchand PR, Keller H, Peters JM, Vazquez M, Gonzalez FJ, Wahli W (1996). The PPARalpha-leukotriene B4 pathway to inflammation control. Nature 384: 39-43.

Forman BM, Chen J, Evans RM (1996). The peroxisome proliferator-activated receptors: ligands and activators. Ann NY Acad Sci 804: 266-275.

Fu J, Gaetani S, Oveisi F, Lo Verme J, Serrano A, Rodríguez De Fonseca $\mathrm{F}$ et al (2003). Oleoylethanolamide regulates feeding and body weight through activation of the nuclear receptor PPARalpha. Nature 425: 90-93.

Gray E, Ginty M, Kemp K, Scolding N, Wilkins A (2011). Peroxisome proliferator-activated receptor-a agonists protect cortical neurons from inflammatory mediators and improve peroxisomal function. Eur J Neurosci 33: 1421-1432.

Hort J, Laczó J, Vyhnálek M, Bojar M, Bures J, Vlcek K (2007). Spatial navigation deficit in amnestic mild cognitive impairment. Proc Natl Acad Sci USA 104: 4042-4047.

Kliewer SA, Forman BM, Blumberg B, Ong ES, Borgmeyer U, Mangelsdorf DJ et al (1994). Differential expression and activation of a family of murine peroxisome proliferatoractivated receptors. Proc Natl Acad Sci USA 91: 7355-7359.

Kuehl Jr FA, Jacob TA, Ganley OH, Ormond RE, Meisinger MAP (1957). The identification of N-(2-hydroxyethyl)-palmitamide as a naturally occurring anti-inflammatory agent. J Am Chem Soc 79: 5577-5578.

Lambert DM, Vandevoorde S, Diependaele G, Govaerts SJ, Robert AR (2001). Anticonvulsant activity of N-palmitoylethanolamide, a putative endocannabinoid, in mice. Epilepsia 42: 321-327.

Lo Verme J, Fu J, Astarita G, La Rana G, Russo R, Calignano A et al (2005a). The nuclear receptor peroxisome proliferator-activated receptor-alpha mediates the anti-inflammatory actions of palmitoylethanolamide. Mol Pharmacol 67: 15-19.

Long DA, Martin AJP (1956). Factor in arachis oil depressing sensitivity to tuberculin in B.C.G.-infected guinea pigs. The Lancet 267: 464-466.

LoVerme J, La Rana G, Russo R, Calignano A, Piomelli D (2005b). The search for the palmitoylethanolamide receptor. Life Sci 77: 1685-1698.

LoVerme J, Russo R, La Rana G, Fu J, Farthing J, Mattace-Raso G et al (2006). Rapid broad-spectrum analgesia through activation of peroxisome proliferator-activated receptor-alpha.J Pharmacol Exp Ther 319: 1051-1061.

Masek K, Perlik F, Klima J, Kahlich R (1974). Prophylactic efficacy of $\mathrm{N} 2$ hydroxyethyl palmitamide (Impulsin) in acute respiratory tract infections. Eur J Clin Pharmacol 7: 415-419.

Maurice T, Duclot F, Meunier J, Naert G, Givalois L, Meffre J et al (2008). Altered memory capacities and response to stress in p300/CBP-associated factor (PCAF) histone acetylase knockout mice. Neuropsychopharmacology 33: 1584-1602.

Maurice T, Lockhart BP, Privat A (1996). Amnesia induced in mice by centrally administered beta-amyloid peptides involves cholinergic dysfunction. Brain Res 706: 181-193.

Mazzari S, Canella R, Petrelli L, Marcolongo G, Leon A (1996). $\mathrm{N}$-(2-hydroxyethyl)hexadecanamide is orally active in reducing edema formation and inflammatory hyperalgesia by downmodulating mast cell activation. Eur J Pharmacol 300: 227-236.

Melis M, Pillolla G, Luchicchi A, Muntoni AL, Yasar S, Goldberg SR et al (2008). Endogenous fatty acid ethanolamides suppress nicotine-induced activation of mesolimbic dopamine neurons through nuclear receptors. J Neurosci 28: 13985-13994.

Olariu A, Tran MH, Yamada K, Mizuno M, Hefco V, Nabeshima T (2001). Memory deficits and increased emotionality induced by beta-amyloid (25-35) are correlated with the reduced acetylcholine release and altered phorbol dibutyrate binding in the hippocampus. J Neural Transm 108: 1065-1079.

Raso GM, Esposito E, Vitiello S, Iacono A, Santoro A, D’Agostino G et al (2011). Palmitoylethanolamide stimulation induces allopregnanolone synthesis in C6 Cells and primary astrocytes: involvement of peroxisome-proliferator activated receptor- $\alpha$. J Neuroendocrinol 23: 591-600.

Sasso O, Russo R, Vitiello S, Mattace Raso G, D’Agostino G, Iacono A et al (2011). Implication of allopregnanolone in the antinociceptive effect of N-palmitoylethanolamide in acute or persistent pain. Pain 153: 33-41.

Schmid AW, Lynch MA, Herron CE (2009). The effects of IL-1 receptor antagonist on beta amyloid mediated depression of LTP in the rat CA1 in vivo. Hippocampus 19: 670-676.

Scuderi C, Esposito G, Blasio A, Valenza M, Arietti P, Steardo Jr L et al (2011). Palmitoylethanolamide counteracts reactive astrogliosis induced by beta-amyloid peptide. J Cell Mol Med 15: 2664-2674.

Solorzano C, Zhu C, Battista N, Astarita G, Lodola A, Rivara S et al (2009). Selective $\mathrm{N}$-acylethanolamine-hydrolyzing acid amidase inhibition reveals a key role for endogenous palmitoylethanolamide in inflammation. Proc Natl Acad Sci USA 106: 20966-20971.

Stellwagen D, Malenka RC (2006). Synaptic scaling mediated by glial TNF-alpha. Nature 440: 1054-1059. 
Tsai SJ, Hong CJ, Liu ME, Hou SJ, Yen FC, Hsieh CH et al (2010). Interleukin-1 beta (C-511T) genetic polymorphism is associated with cognitive performance in elderly males without dementia. Neurobiol Aging 31: 1950-1955.

Willson TM, Brown PJ, Sternbach DD, Henke BR (2000). The PPARs: from orphan receptors to drug discovery. J Med Chem 43: $527-550$.
Yamada K, Tanaka T, Han D, Senzaki K, Kameyama T, Nabeshima $T$ (1999). Protective effects of idebenone and alpha-tocopherol on beta-amyloid-(1-42)-induced learning and memory deficits in rats: implication of oxidative stress in beta-amyloid-induced neurotoxicity in vivo. Eur J Neurosci 11: 83-90.

Zawia NH, Lahiri DK, Cardozo-Pelaez F (2009). Epigenetics, oxidative stress, and Alzheimer disease. Free Radic Biol Med 46: 1241-1249. 